\title{
CORRIGENDUM
}

\section{Stearoyl-CoA-desaturase 1 regulates lung cancer stemness via stabilization and nuclear localization of YAP/TAZ}

A Noto, C De Vitis, ME Pisanu, G Roscilli, G Ricci, A Catizone, G Sorrentino, G Chianese, O Taglialatela-Scafati, D Trisciuoglio,

D Del Bufalo, M Di Martile, A Di Napoli, L Ruco, S Costantini, Z Jakopin, A Budillon, G Melino, G Del Sal, G Ciliberto and R Mancini

Oncogene (2017) 36, 4671-4672; doi:10.1038/onc.2017.212; published online 19 June 2017

Correction to: Oncogene (2017) 36, 4573-4584; doi:10.1038/onc. 2017.75; published online 3 April 2017.

Since the publication of the above article, the authors have noticed that the red line and the blue line were accidently inverted in the annotation inside Figure $6 c$. Red line should indicate $\beta$-cat_low/scd1_low, while blue line should indicate $\beta$-cat_high/scd1_high.
The corrected Figure 6 is below.

This correction has no effects on the results/conclusions of the paper.

The authors would like to apologise to the readers for any inconvenience this may have caused. 

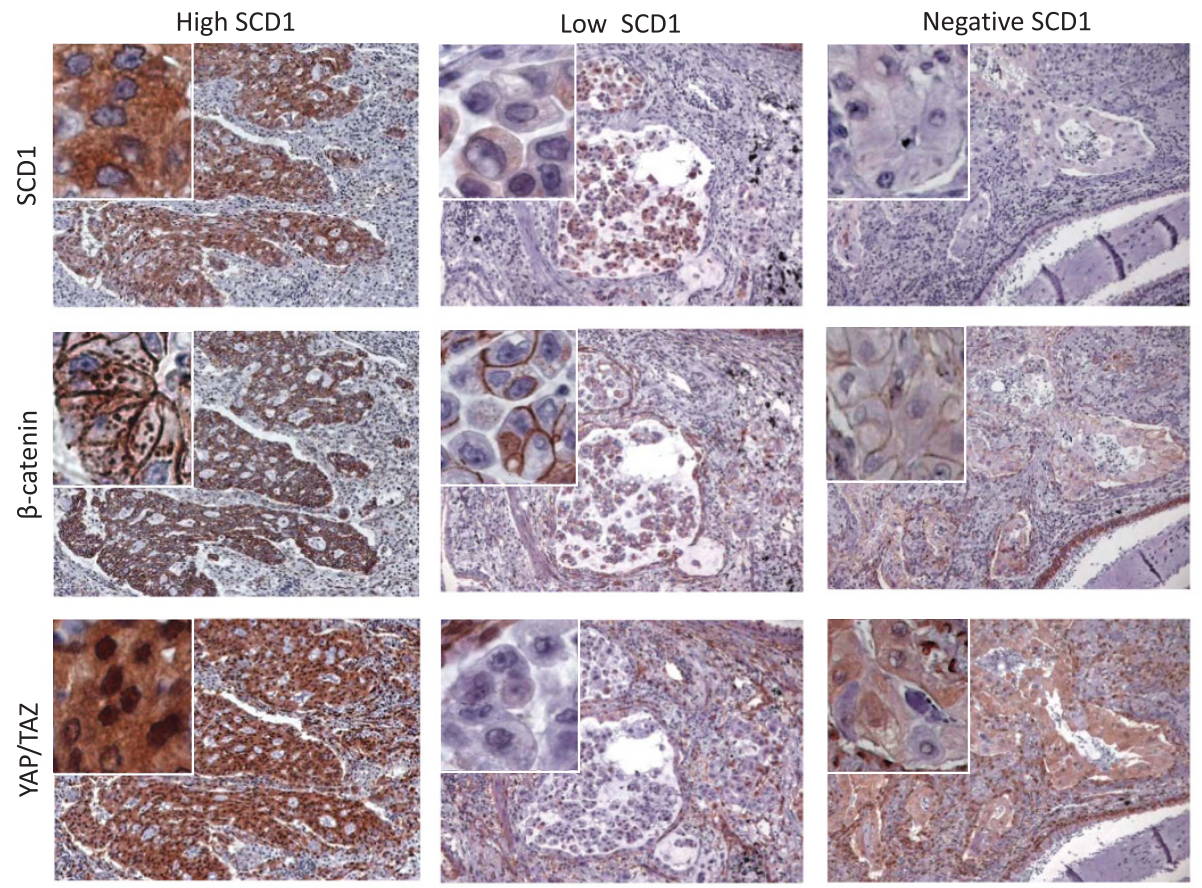

b

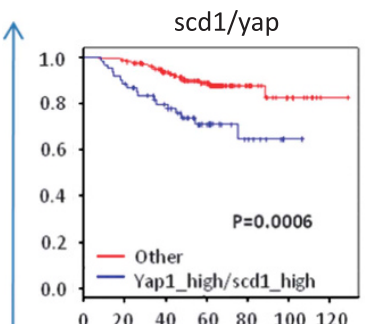

ธั

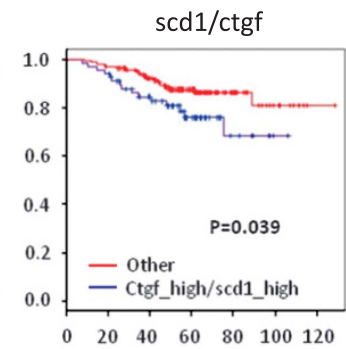

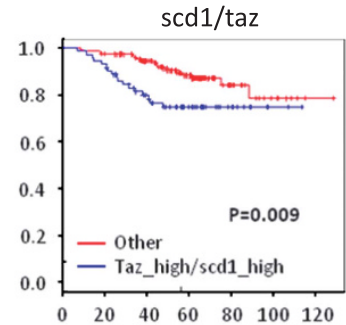

scd1/birc5

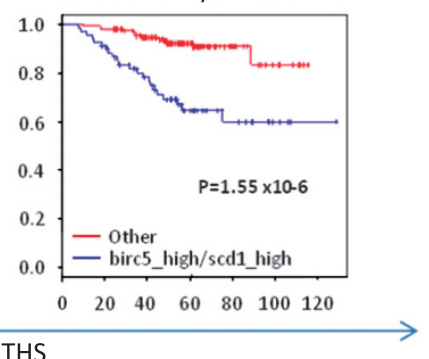

ะ

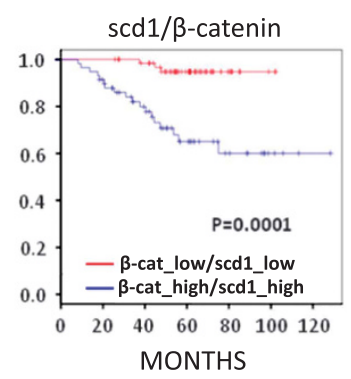

d

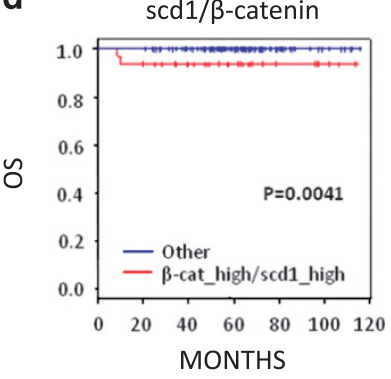

Figure 6. SCD1, YAP/TAZ and $\beta$-catenin co-expression in patients with adenocarcinoma. (a) Representative immunohistochemistry images for $\beta$-catenin, SCD1 and YAP/TAZ. In the left panel, a sample with strong expression of SCD1 (high SCD1). In the middle and right panel, intermediate and negative expression of SCD1 are shown respectively (low SCD1 and negative SCD1). Original magnification $\times 100$, inset $\times 400$ ). In the tumor tissue, SCD1 showed cytoplasmic and rarely nuclear staining, YAP and TAZ stained the cytoplasms and the nuclei, and $\beta$-catenin had a membranous and occasionally a granular cytoplasmic positivity. Only scattered $\beta$-catenin-positive nuclei were observed. (b) Upper panel: Kaplan-Meier curves showing the overall survival of patients expressing higher level of both scd1 and yap mRNA (scd1 high/ yap_high) or higher level of both scd1 and taz mRNA (scd1_high/taz_high) compared with patients having the two genes not correlated (other). Lower panel: similar analysis was performed to analyze the overall survival of patients expressing higher level of scd1 and ctgf (scd1_high/ctgf_high) or scd1 and birc5 (scd1_high/birc5_high). (c) Kaplan-Meier curves showing the overall survival of patients with scd1 and $\beta$-catenin mRNA at higher level compared with patients showing lower scd 1 and $\beta$-catenin mRNA level. (d) Kaplan-Meier curves showing the overall survival of patients with tumor recurrence. Analysis was carried out in patients with scd 1 and $\beta$-catenin mRNA both at higher level compared with patients showing lower scd1 and $\beta$-catenin mRNA. 